\title{
AVALIAÇÃO E ESPACIALIZAÇÃO DA EROSIVIDADE DA CHUVA NO VALE DO RIO DOCE, REGIÃO CENTRO- LESTE DO ESTADO DE MINAS GERAIS ${ }^{(1)}$
}

\author{
Mayesse Aparecida da Silva ${ }^{(2)}$, Marx Leandro Naves Silva ${ }^{(3)}$, Nilton \\ Curi $^{(3)}$, Gérson Rodrigues dos Santos ${ }^{(4)}$, João José Granate de Sá e \\ Melo Marques ${ }^{(3)}$, Michele Duarte de Menezes ${ }^{(5)} \&$ Fernando Palha \\ Leite $^{(6)}$
}

\begin{abstract}
RESUMO
Um fator muito atuante no processo erosivo e considerado de grande importância é o fator R, denominado erosividade da chuva. Esse fator é um dos componentes da equação universal de perdas de solo. Estudos de variabilidade espacial têm sido realizados almejando definir a distribuição espacial do fator $\mathbf{R}$ para determinada região. Objetivou-se com este trabalho calcular a erosividade da chuva (fator $\mathrm{R}$ - $\mathrm{EI}_{30}$ ) e gerar os mapas de espacialização desta. $\mathrm{O}$ estudo foi realizado em áreas experimentais de plantios de eucalipto localizadas em nove municípios, no Vale do Rio Doce, região centro-leste do Estado de Minas Gerais. Foram utilizados dados pluviográficos referentes ao período de janeiro de 2005 a dezembro de 2008. A espacialização da erosividade foi feita com base nos princípios da geoestatística, e a interpolação dos dados, por meio da krigagem. Os índices de erosividade anual variaram de 7.970 a $18.646 \mathrm{MJ} \mathrm{mm} \mathrm{ha}^{-1} \mathrm{~h}^{-1}$ ano-1. $^{-} \mathrm{O}$ alcance para o índice de erosividade mensal variou de 10 a $177 \mathrm{~km}$, e o anual foi de cerca de $52 \mathrm{~km}$.
\end{abstract}

Termos de indexação: fator $\mathrm{R}\left(\mathrm{EI}_{30}\right)$, potencial erosivo da chuva, variabilidade espacial, geoestatística.

\footnotetext{
(1) Recebido para publicação em junho de 2009 e aprovado em maio de 2010.

(2) Engenheira Florestal, Doutoranda, DCS, Universidade Federal de Lavras - UFLA. Caixa Postal 37, CEP 37200-000 Lavras.(MG). Bolsista da CAPES. E-mail: mayesse@gmail.com

(3) Professor, DCS, UFLA. Bolsistas do CNPq. E-mails: marx@ufla.br; niltcuri@ufla.br; jmarques@ufla.br

(4) Doutorando em Estatística e Experimentação Agropecuária - Área de Geoestatística, UFLA-DEX. E-mail: prof.gersonrodrigues@gmail.com

(5) Engenheira-Agrônoma, Doutoranda, DCS, UFLA. Bolsista do CNPq. E-mail: michelinha_duarte@hotmail.com

(6) Pesquisador da CENIBRA S.A. Caixa Postal 100, Bairro Horto, CEP 35162-970 Ipatinga (MG). E-mail: fernando.leite@cenibra.com.br
} 


\title{
SUMMARY: EVALUATIONAND SPATIALIZATIONOF RAINFALL EROSIVITY IN THE RIO DOCE VALLEY, CENTRAL-EASTERN REGION OF MINAS GERAIS, BRAZIL
}

\begin{abstract}
A very active and influential parameter in the erosive process is the $R$ factor, called rainfall erosivity. This factor is one of the components of the universal soil loss equation. Studies in spatial variability have been conducted in an attempt to define the spatial distribution of the $R$ factor for a given region. This study aimed to calculate the rainfall erosivity ( $R$ factor - EI $I_{30}$ ) to generate spatial maps. The study was conducted in experimental areas of eucalyptus stands in nine counties of the Rio Doce Valley, Central-Eastern region of Minas Gerais state, Brazil. Rainfall data from January 2005 to December 2008 were used. Erosivity was spatialized according to geostatistical principles and data interpolation using kriging. The annual rainfall erosivity indexes ranged from 7,970 to $18,646 \mathrm{MJ} \mathrm{mm} \mathrm{ha}^{-1} \mathrm{~h}^{-1}$ year-1. The reaching distance of the monthly erosivity index varied from 10 to $177 \mathrm{~km}$, and was $52 \mathrm{~km}$ for the annual index.
\end{abstract}

Index terms: $R$ factor $\left(E I_{30}\right)$, rainfall erosion potential, spatial variability, geostatistics.

\section{INTRODUÇÃO}

Mais da metade dos plantios de eucalipto no Brasil (51,77\%) encontra-se no Estado de Minas Gerais (SBS, 2001), concentrando-se nas regiões do Vale do Rio Doce, Centro-Oeste, Noroeste, Centro/Norte e Vale do Jequitinhonha/Mucuri (Belo Horizonte, 2008).

A região do Vale do Rio Doce, atualmente, é uma das mais degradadas pela erosão hídrica no Estado de Minas Gerais. Ela sofreu um efeito antrópico muito impactante nos últimos 50-60 anos, que incluiu: desmatamento da floresta nativa, uso indiscriminado do fogo e manejo incorreto das pastagens e total desrespeito à capacidade de suporte das pastagens, 0 que, aliado ao relevo movimentado dominante e à ocorrência de chuvas erosivas concentradas, resultou num quadro dramático de degradação do solo, decorrente do processo de erosão acelerada, inclusive no topo dos morros (áreas de recarga do lençol freático). Normalmente, os plantios florestais encontram-se em áreas de relevo acidentado, em solos com baixa fertilidade natural e em antigas áreas agrícolas degradadas. Esses aspectos justificam estudos relativos ao monitoramento da erosão hídrica na região, visando ações de planejamento de práticas de conservação do solo e da água (Oliveira et al., 2009), principalmente esta última.

No processo erosivo, um fator muito atuante e considerado de grande importância é o fator R, denominado erosividade da chuva, que compõe a equação universal de perdas de solo e é um índice numérico que expressa a capacidade da chuva, esperada em dada localidade, de causar erosão hídrica em uma área sem proteção (Bertoni \& Lombardi Neto, 1993). Ele pode ser expresso por meio de índices que se baseiam nas características físicas das chuvas de cada região (Cabral et al., 2005), sendo o $\mathrm{EI}_{30}$ o mais utilizado em condições brasileiras. Considerado o índice mais adequado à realidade intertropical (Bertoni \& Lombardi Neto, 1993; Albuquerque et al., 1994; Alves, 2000), o $\mathrm{EI}_{30}$ representa o produto da energia cinética com que a gota de chuva atinge o solo pela sua intensidade máxima. Segundo Bertoni \& Lombardi Neto (1993), esse produto representa um termo de interação que mede o efeito de como a erosão por impacto, salpico e turbulência se combina com a enxurrada para transportar as partículas de solo desprendidas.

A determinação dos valores da erosividade, ao longo do ano, permite identificar os meses nos quais os riscos de perdas de solo e água são mais elevados - razão por que exerce papel relevante no planejamento de práticas conservacionistas fundamentadas na máxima cobertura do solo nas épocas críticas de maior capacidade erosiva das chuvas (Wischmeier \& Smith, 1978; Bertoni \& Lombardi Neto, 1993; Hudson, 1995). Em razão disso, diversos pesquisadores têm realizado estudos de variabilidade espacial almejando definir a distribuição espacial da erosividade da chuva em determinada região, a exemplo dos trabalhos de Vieira \& Lombardi Neto (1995), que estudaram a variabilidade espacial da erosividade da chuva para o Estado de São Paulo; Silva (2004), para o Brasil; Aquino (2005), para a região Sul de Minas Gerais; Gonçalves et al. (2006) e Montebeller (2007), para o Estado do Rio de Janeiro; Mello et al. (2007), para o Estado de Minas Gerais; e Men et al. (2008), para a Província de Hebei, na China.

Sabendo da importância da erosividade no processo erosivo, particularmente em regiões muito degradadas e com chuvas erosivas concentradas, objetivou-se com este trabalho calcular os valores de erosividade (fator R - EI $\mathrm{I}_{30}$ ) e gerar os mapas de espacialização da erosividade no Vale do Rio Doce, região centro-leste do Estado de Minas Gerais, para o período de 2005 a 2008. 


\section{MATERIAL E MÉTODOS}

\section{Localização da área experimental}

O estudo foi realizado em estações pluviográficas instaladas em áreas experimentais de plantios de eucalipto, localizadas em nove municípios (Açucena, Antônio Dias, Belo Oriente, Caratinga, Peçanha, Sabinópolis, Santa Bárbara, Santo Antônio do Itambé e São Domingos do Prata), nas coordenadas UTM 609499 de longitude E e 7718765 de latitude S (Datum WGS 1984 Zona 23 S) no Vale do Rio Doce, região centro-leste do Estado de Minas Gerais (Figura 1). Os municípios se dividem em três grupos climáticos, segundo a classificação de Köppen: Aw - clima tropical, com inverno seco e estação chuvosa no verão, e estação seca manifestando-se entre os meses de maio e setembro (Açucena, Belo Oriente e Caratinga); Cwaclima de inverno e verão chuvoso, com temperatura do mês mais frio inferior a $18{ }^{\circ} \mathrm{C}$ e a do mais quente ultrapassando $22^{\circ} \mathrm{C}$, e estação seca ocorrendo entre os meses de abril e setembro (Peçanha, Sabinópolis e Santo Antônio do Itambé); e Cwb - clima mesotérmico de inverno seco e verão fresco, com temperaturas abaixo de $22{ }^{\circ} \mathrm{C}$, sendo característico de áreas de maior altitude (Antônio Dias, Santa Bárbara e São Domingos do Prata) (CENIBRA, 2001). As principais classes de solos na região são os Latossolos, o relevo é principalmente ondulado e forte ondulado, a vegetação nativa é representada pela floresta subcaducifólia e o uso atual do solo é predominantemente com pastagens e eucalipto (CENIBRA, 2001).

\section{Determinação do índice de erosividade $\mathrm{EI}_{30}$ a partir de dados pluviográficos e pluviométricos}

De acordo com Wischmeier \& Smith (1978), para se obter um fator R confiável, estima-se que sejam necessários 20 anos de coleta de dados; contudo, vários trabalhos sobre erosividade têm sido realizados em condições brasileiras, abrangendo um número de anos inferior ao ideal, em função da grande dificuldade de obtenção da base de dados pluviográficos em nosso país (Morais et al., 1991; Bertol, 1993; Gonçalves et al., 2006; Oliveira et al., 2009). Para este estudo, foram utilizados dados pluviográficos referentes ao período de janeiro de 2005 a dezembro de 2008, obtidos de estações climatológicas automatizadas, distribuídas nos municípios de abrangência do estudo, que geraram dados a cada 5 min (Figura 1). A partir das precipitações, foram calculadas as energias cinéticas totais das chuvas para cada evento. Foram consideradas chuvas individuais aquelas separadas por mais de $6 \mathrm{~h}$. As chuvas menores que $10 \mathrm{~mm}$, com intensidade máxima menor que $24 \mathrm{~mm} \mathrm{~h}^{-1} \mathrm{em} 15 \mathrm{~min}$, ou com energia cinética menor que 3,6 MJ, foram consideradas não erosivas (De Maria, 1994). Para o cálculo da energia cinética (Ec), utilizou-se a equação proposta por Wischmeier \& Smith (1958):

$$
E c=0,119+0,0873 \log I
$$

em que Ec = energia cinética $\left(\mathrm{MJ} \mathrm{ha}^{-1} \mathrm{~mm}^{-1}\right) ;$ e I = intensidade média da chuva $\left(\mathrm{mm} \mathrm{h}^{-1}\right)$.

O índice de erosividade $\mathrm{EI}_{30}\left(\mathrm{MJ} \mathrm{mm} \mathrm{ha}^{-1} \mathrm{~h}^{-1}\right)$ de cada chuva individual erosiva foi calculado multiplicando-

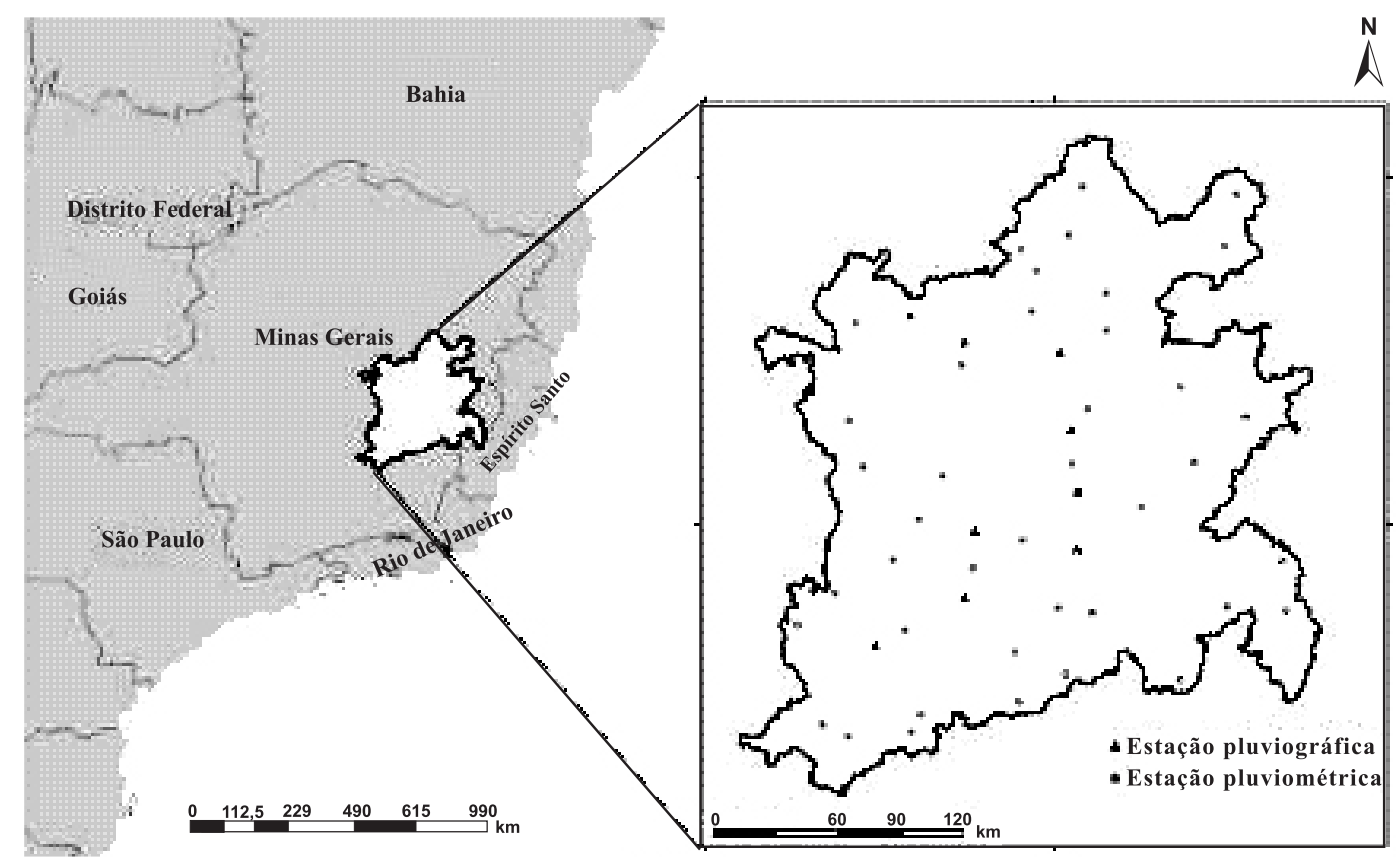

Figura 1. Mapa de localização das estações pluviográficas e pluviométricas na região do Vale do Rio Doce, MG. 
se a energia cinética pela sua intensidade máxima $\left(\mathrm{mm} \mathrm{h}^{-1}\right) . \mathrm{O} \mathrm{EI}_{30}$ mensal foi calculado pelo somatório dos valores desse índice para todas as chuvas individuais erosivas que ocorreram em cada mês do ano, cuja soma, por sua vez, caracterizou o $\mathrm{EI}_{30}$ anual (Wischmeier \& Smith, 1958). A erosividade foi classificada segundo Foster et al. (1981).

Considerando a baixa densidade de pontos com dados pluviográficos para analisar a variabilidade espacial dos índices de erosividade, foram também utilizados, neste trabalho, dados pluviométricos, obtidos do Sistema de Informações Hidrológicas da Agência Nacional de Águas (ANA) de 42 municípios da região do estudo (Figura 1).

Esses dados foram utilizados para gerar índices de erosividade a partir de equações de regressão obtidas entre valores mensais de $\mathrm{EI}_{30}$ e precipitação mensal ou índices pluviométricos, para os 42 municípios incluídos na figura 1. Devido às falhas costumeiras nas séries históricas, não foi possível selecionar um período comum de dados para todas as estações pluviométricas para fins de determinação dos índices de erosividade das chuvas; assim, foram utilizadas séries históricas com períodos diferentes entre os municípios, variando de 16 a 67 anos. O índice de chuva usado nas relações não lineares foi proposto por Fournier (1956) e modificado por Lombardi Neto (1977):

$$
R_{c}=p^{2} \times P^{-1}
$$

em que $\mathrm{Rc}=$ coeficiente de $\operatorname{chuva}(\mathrm{mm}) ; \mathrm{p}=$ precipitação pluvial média mensal $(\mathrm{mm})$; e $\mathrm{P}=$ precipitação pluvial média anual ( $\mathrm{mm})$.

\section{Espacialização do índice de erosividade}

A espacialização da erosividade foi feita com base nos princípios da geoestatística, que leva em consideração a localização geográfica e a dependência espacial. Portanto, foram ajustados os semivariogramas para erosividade mensal e anual.

Os semivariogramas expressam o comportamento espacial da variável regionalizada ou de seus resíduos e mostram o tamanho da zona de influência em torno de uma amostra, a variação nas diferentes direções do terreno, bem como a continuidade da característica estudada no terreno (Landim, 1998; Zimback, 2003). A construção do semivariograma teve como base a seguinte expressão (Journel, 1989).

$$
\hat{\gamma}(h)=\frac{1}{2 \times N(h)} \times \sum_{i=1}^{N(h)}[Z(s+h)-Z(s)]^{2}
$$

em que $\hat{\gamma}(h)$ é o estimador da semivariância populacional entre pares de pontos; $\mathrm{Z}(\mathrm{s}+\mathrm{h})$ e $\mathrm{Z}(\mathrm{s})$ são valores medidos em locais afastados entre si pela distância $h$; e $\mathrm{N}(\mathrm{h})$ é o número de pares de pontos separados pela mesma distância h.
Na construção dos semivariogramas experimentais foram utilizados os valores de erosividade calculados para as estações pluviométricas e pluviográficas, totalizando 51 pontos. Com isso, obteve-se maior número de pontos amostrais, garantindo melhor ajuste do semivariograma teórico.

Os modelos de semivariogramas ajustados neste trabalho foram, principalmente, o gaussiano e, em alguns casos, o exponencial e o esférico. Após os ajustes e a validação dos modelos, por intermédio da validação cruzada (cross-validation), procedeu-se à interpolação dos dados por meio da krigagem, gerando mapas que mostram o comportamento espacial da erosividade na região do Vale do Rio Doce.

Todas as análises geoestatísticas foram realizadas no programa R, por meio do pacote GeoR (Ribeiro Junior \& Diggle, 2001).

\section{RESULTADOS E DISCUSSÃO}

A maiores precipitações pluviais, no geral, ocorreram nos meses de novembro e dezembro, correspondendo a 39\% do total anual médio precipitado, seguidos pelos meses de janeiro a março, os quais contribuíram com 40\% (Quadro 1). Esses resultados são próximos aos observados por Oliveira et al. (2005), os quais verificaram que para o Estado de Minas Gerais as chuvas de novembro a fevereiro representam cerca de 70\% da precipitação pluvial anual histórica. Já Souza et al. (2006) encontraram, para a mesma região deste estudo, valores mais elevados de precipitação nos meses de outubro a março, representando $87 \%$ do total precipitado nos dois primeiros meses e $84 \%$ no último.

Entre os municípios, Açucena foi o que apresentou período chuvoso mais extenso, compreendendo os meses de novembro a abril. No mês de abril, a precipitação pluvial média foi de $196,6 \mathrm{~mm}$, enquanto o segundo município de maior precipitação no mesmo mês foi Santo Antônio do Itambé, com $82 \mathrm{~mm}$. Normalmente, a maior parte das empresas florestais realiza os plantios de eucalipto praticamente o ano todo. Sabendo os meses de maiores riscos à erosão por consequência de chuvas intensas (erosivas), pode-se planejar o manejo dos plantios, evitando que durante os períodos mais críticos o solo esteja sem proteção.

Foram estudadas 1.359 chuvas, das quais 472 foram consideradas erosivas (35\%) e 887 não erosivas (65\%). Os meses mais críticos foram de janeiro a março e novembro a dezembro, que contribuíram com $62 \%$ do total das chuvas erosivas ocorridas no período de estudo; o mês de novembro contribuiu com o maior número (15\%). Em regiões tropicais é comum a ocorrência de chuvas erosivas, principalmente no período de maior precipitação, podendo chegar a 40\% do total anual das chuvas, ao passo que, em regiões de clima temperado, apenas $5 \%$ delas são consideradas erosivas (Hudson, 1971). 
Quadro 1. Distribuição dos valores médios mensais e anual da precipitação pluvial, observados nos anos de 2005 a 2008, em nove municípios, na região do Vale do Rio Doce, MG

\begin{tabular}{|c|c|c|c|c|c|c|c|c|c|}
\hline \multirow{2}{*}{ Mês } & \multicolumn{9}{|c|}{ Município } \\
\hline & 1 & 2 & 3 & 4 & 5 & 6 & 7 & 8 & 9 \\
\hline Janeiro & 268,3 & 179,8 & 190,3 & 187,7 & 160,4 & 127,3 & 217,5 & 197,9 & 202,1 \\
\hline Fevereiro & 113,7 & 125,2 & 123,0 & 153,9 & 123,3 & 191,8 & 162,3 & 114,9 & 145,4 \\
\hline Março & 135,1 & 137,2 & 192,5 & 239,2 & 106,9 & 155,9 & 190,8 & 125,4 & 96,4 \\
\hline Abril & 21,9 & 75,1 & 69,8 & 82,0 & 67,0 & 73,4 & 54,6 & 44,9 & 196,6 \\
\hline Maio & 16,2 & 16,6 & 14,9 & 29,7 & 30,6 & 21,6 & 20,1 & 21,3 & 27,0 \\
\hline Junho & 11,6 & 16,8 & 19,6 & 4,8 & 10,1 & 8,7 & 9,4 & 6,6 & 21,8 \\
\hline Julho & 2,0 & 11,7 & 6,9 & 7,4 & 2,5 & 1,1 & 6,2 & 4,4 & 9,3 \\
\hline Agosto & 13,0 & 6,2 & 2,6 & 2,5 & 22,6 & 12,5 & 19,4 & 5,2 & 19,9 \\
\hline Setembro & 43,2 & 38,8 & 48,9 & 72,6 & 55,0 & 35,1 & 66,6 & 39,8 & 65,6 \\
\hline Outubro & 94,4 & 48,1 & 64,7 & 117,2 & 73,7 & 61,3 & 90,4 & 66,3 & 64,6 \\
\hline Novembro & 208,5 & 216,5 & 223,9 & 257,3 & 222,0 & 310,0 & 237,4 & 238,3 & 332,9 \\
\hline Dezembro & 175,0 & 228,7 & 241,7 & 256,6 & 163,4 & 224,7 & 198,1 & 213,7 & 299,9 \\
\hline Anual & $1.102,8$ & $1.100,7$ & $1.198,8$ & $1.411,0$ & $1.037,6$ & $1.223,3$ & $1.272,7$ & $1.078,6$ & $1.481,4$ \\
\hline
\end{tabular}

1: São Domingos do Prata; 2: Peçanha; 3: Antônio Dias; 4: Santo Antônio do Itambé; 5: Caratinga; 6: Belo Oriente; 7: Santa Bárbara; 8: Sabinópolis; 9: Açucena.

A média mensal do índice de erosividade foi maior no período de maior precipitação, que compreende os meses iniciais do ano (janeiro a março) e os meses finais (novembro e dezembro), contribuindo, em média, com $83 \%$ do valor da erosividade total para o período de estudo (Quadro 2). Nesse período, a precipitação pluvial e a sua intensidade ocorrem de forma mais acentuada, característica de chuvas convectivas. As chuvas convectivas são típicas de regiões tropicais e caracterizam-se por serem de grande intensidade e curta duração. Durante a estação do verão, a região do Vale do Rio Doce é afetada por fenômenos de circulação atmosférica influenciados pela predominância de sistemas convectivos associados ao aquecimento continental e pela Zona de Convergência do Atlântico Sul (ZCAS) (Cupolillo et al., 2006). Isso faz com que essa região apresente chuvas bastante intensas, acarretando riscos no manejo desses solos durante esse período.

A erosividade, entre os municípios, apresentou variações, Açucena foi o único município que apresentou um índice de erosividade para o mês de abril maior que os registrados para fevereiro e março, considerados meses de elevados índices de erosividade por outros autores, como Bazzano et al. (2007), Martins (2005) e Aquino (2005). A erosividade nesse mês foi de $2.357 \mathrm{MJ} \mathrm{mm} \mathrm{ha}^{-1} \mathrm{~h}^{-1} \mathrm{mês}^{-1}$, enquanto o segundo município de maior erosividade no mesmo mês foi Peçanha, com $629 \mathrm{MJ} \mathrm{mm} \mathrm{ha}^{-1} \mathrm{~h}^{-1} \mathrm{mês}^{-1}$. Elevado valor de erosividade para o mês de abril, no Brasil, também foi observado por Cassol et al. (2008), os quais encontraram um valor de $1.269 \mathrm{MJ} \mathrm{mm} \mathrm{ha}^{-1} \mathrm{~h}^{-1}$ mês $\mathrm{s}^{-1}$ para o município de São Borja, RS. Valores de erosividade mensal acima de $500 \mathrm{MJ} \mathrm{mm} \mathrm{ha-1} \mathrm{h}^{-1}$ mês $^{-1}$ podem ser considerados críticos (Rufino, 1986).

O valor médio da erosividade anual, para a região, foi de $11.656 \mathrm{MJ} \mathrm{mm} \mathrm{ha}^{-1} \mathrm{~h}^{-1} \mathrm{ano}^{-1}$, enquadrando-se na faixa de variação de 3.116 a $20.035 \mathrm{MJ} \mathrm{mm} \mathrm{ha}^{-1} \mathrm{~h}^{-1}$ ano $^{-1}$, encontrada por Silva (2004) por meio de mapa de erosividade da chuva para o Brasil, e próximo ao limite superior da faixa estabelecida para o País, que é de 5.000 a $12.000 \mathrm{MJ} \mathrm{mm} \mathrm{ha}^{-1} \mathrm{~h}^{-1} \mathrm{ano}^{-1}$, de acordo com Cogo (1988). Para Manaus (AM), foi determinado um valor elevado de erosividade anual média, na ordem de 14.129 MJ mm ha-1 $\mathrm{h}^{-1}$ ano $^{-1}$ (Oliveira Junior \& Medina, 1990). Estudos desenvolvidos por Cassol et al. (2008) mostraram para São Borja, RS, o valor médio de erosividade anual de $9.571 \mathrm{MJ} \mathrm{mm} \mathrm{ha} \mathrm{h} \mathrm{h}^{-1}$ ano $^{-1}$; já Dias \& Silva (2003) encontraram valores mais baixos para Fortaleza, CE, na ordem de 6.774 MJ mm ha-1 $\mathrm{h}^{-1} \mathrm{ano}^{-1}$, em consonância com os valores totais diferenciais de precipitação e sua distribuição ao longo dos anos.

Entre os municípios, os índices de erosividade anual variaram de 7.970 a $18.646 \mathrm{MJ} \mathrm{mm} \mathrm{ha-1} \mathrm{h}^{-1} \mathrm{ano}^{-1}$ (Quadro 2); valores na ordem de $18.510 \mathrm{MJ} \mathrm{mm} \mathrm{ha}^{-1}$ $\mathrm{h}^{-1} \mathrm{ano}^{-1}$ foram observados por Salako et al. (1995) para a região centro sul da Nigéria. Os municípios que apresentaram o menor e o maior índice foram Antônio Dias e Açucena, considerados alto e muito alto, respectivamente, segundo classificação proposta por Foster et al. (1981).

Segundo Wischmeier (1976), são necessários pelo menos 20 anos de informações no cálculo da erosividade no sentido de incluir variações cíclicas comuns aos parâmetros climáticos, as quais refletem-se na grande variabilidade temporal das chuvas e de sua erosividade. Considerando a escassez de informações de estações pluviográficas no Brasil, vários pesquisadores vêm utilizando correlações entre as erosividades, determinadas em registros pluviográficos detalhados, para determinar a erosividade por meio de séries históricas para diversas regiões (Silva \& Dias, 2003; 
Quadro 2. Distribuição dos valores médios mensais e anual do índice de erosividade, $\mathrm{EI}_{30}$, observados nos anos de 2005 a 2008, em nove municípios, na região do Vale do Rio Doce, MG

\begin{tabular}{|c|c|c|c|c|c|c|c|c|c|}
\hline \multirow[b]{2}{*}{ Mês } & \multicolumn{9}{|c|}{ Município } \\
\hline & 1 & 2 & 3 & 4 & 5 & 6 & 7 & 8 & 9 \\
\hline & & & & & $\mathrm{J} \mathrm{mm} \mathrm{ha-}$ & & & & \\
\hline Janeiro & 7.374 & 1.309 & 1.554 & 1.846 & 1.183 & 1.162 & 1.315 & 2.193 & 5.823 \\
\hline Fevereiro & 995 & 1.021 & 889 & 1.525 & 1.553 & 4.549 & 1.812 & 947 & 1.656 \\
\hline Março & 639 & 1.249 & 1.257 & 2.525 & 1.041 & 1.327 & 1.260 & 692 & 1.411 \\
\hline Abril & 10 & 629 & 186 & 427 & 338 & 422 & 177 & 96 & 2.357 \\
\hline Maio & 36 & 11 & 17 & 163 & 313 & 207 & 102 & 149 & 251 \\
\hline Junho & 33 & 73 & 7 & 0 & 96 & 17 & 33 & 0 & 36 \\
\hline Julho & 1 & 0 & 1 & 8 & 1 & 0 & 9 & 5 & 5 \\
\hline Agosto & 208 & 1 & 151 & 1 & 245 & 108 & 185 & 1 & 126 \\
\hline Setembro & 137 & 242 & 170 & 1.260 & 532 & 119 & 430 & 189 & 314 \\
\hline Outubro & 810 & 309 & 306 & 2.751 & 1.529 & 547 & 700 & 396 & 245 \\
\hline Novembro & 1.562 & 1.575 & 1.227 & 2.149 & 2.007 & 2.457 & 2.211 & 2.209 & 2.517 \\
\hline Dezembro & 1.342 & 2.594 & 2.204 & 2.627 & 1.275 & 2.003 & 911 & 1.793 & 3.904 \\
\hline Anual & 13.145 & 9.013 & 7.970 & 15.280 & 10.115 & 12.919 & 9.145 & 8.670 & 18.646 \\
\hline
\end{tabular}

1: São Domingos do Prata; 2: Peçanha; 3: Antônio Dias; 4: Santo Antônio do Itambé; 5: Caratinga; 6: Belo Oriente; 7: Santa Bárbara; 8: Sabinópolis; 9: Açucena.

Silva, 2004; Cabral et al., 2005; Mello et al., 2007; Montebeller, 2007; Men et al., 2008).

Para este trabalho, foram ajustadas equações de regressão para a estimativa do $\mathrm{EI}_{30}$ de cada estação analisada e a partir delas obtidos os valores de erosividade para as séries históricas (Quadro 3). Vale ressaltar que essas equações representam uma prévia para determinação da erosividade da chuva nessa região, sendo importante a continuidade da análise dos dados no tempo para aprimorar os resultados aqui obtidos.

A variância dos dados e os parâmetros dos semivariogramas ajustados encontram-se no quadro 4. Os modelos foram validados por meio da validação cruzada (cross-validation); para todos os meses, exceto junho, novembro e dezembro, o modelo que melhor se ajustou aos dados foi o gaussiano.

Quadro 3. Equações de regressão ajustadas entre o índice de erosividade mensal médio $\mathrm{EI}_{30}$ (MJ mm ha ${ }^{-1} \mathrm{~h}^{-1}$ mês $^{-1}$ ) e a precipitação média mensal p ( $\mathrm{mm})$ ou o coeficiente de chuva Rc para cada município

\begin{tabular}{lll}
\hline \multicolumn{1}{c}{ Município } & \multicolumn{1}{c}{ Equações } & $\mathbf{R}^{\mathbf{2}}$ \\
\hline Açucena & $\mathrm{EI}_{30}=158,35 \times \mathrm{Rc}^{0,85}$ & 0,88 \\
Antônio Dias & $\mathrm{EI}_{30}=7,84 \times \mathrm{p}-119,27$ & 0,90 \\
Belo Oriente & $\mathrm{EI}_{30}=215,40 \times \mathrm{Rc}^{0,65}$ & 0,89 \\
Caratinga & $\mathrm{EI}_{30}=321,63 \times \mathrm{Rc}^{0,48}$ & 0,86 \\
Peçanha & $\mathrm{EI}_{30}=9,63 \times \mathrm{p}-141,07$ & 0,90 \\
Sabinópolis & $\mathrm{EI}_{30}=123,33 \times \mathrm{Rc}^{0,74}$ & 0,95 \\
Santa Bárbara & $\mathrm{EI}_{30}=170,59 \times \mathrm{Rc}^{0,64}$ & 0,93 \\
Santo Antônio do Itambé & $\mathrm{EI}_{30}=179,33 \times \mathrm{Rc}^{0,77}$ & 0,90 \\
São Domingos do Prata & $\mathrm{EI}_{30}=114,42 \times \mathrm{Rc}^{0,81}$ & 0,86 \\
\hline
\end{tabular}

A erosividade anual produziu um semivariograma com alcance na ordem de $52 \mathrm{~km}$, ou seja, dentro de um raio de $52 \mathrm{~km}$, qualquer ponto da região será influenciado por todos os outros. O alcance para o índice de erosividade mensal variou de $10 \mathrm{~km}$ em outubro a $177 \mathrm{~km}$ em junho. Outros autores encontraram diferentes alcances para a erosividade, indicando que pode haver variações de um local para outro. Vieira \& Lombardi Neto (1995) encontraram valores de alcance de 70 km para esse índice no Estado de São Paulo; Aquino (2005) constatou, na região sul do Estado de Minas Gerais, variação de 20 a 187 km; e Montebeller et al. (2007) encontraram valores de alcance que variaram de 43 a $56 \mathrm{~km}$ no Estado do Rio de Janeiro. Em média, neste estudo, a erosividade mensal apresentou um alcance de $46 \mathrm{~km}$. Assim, estações climatológicas distantes uma da outra, em média, $46 \mathrm{~km}$ seriam suficientes para explicar o comportamento da erosividade na região.

$\mathrm{Na}$ figura 2, pode-se ver o semivariograma e a espacialização do índice de erosividade anual para a região do Vale do Rio Doce, a qual apresenta elevados índices de erosividade, classificados como alto e muito alto. No geral, a região apresentou erosividade de 8.000 a $13.000 \mathrm{MJ} \mathrm{mm} \mathrm{ha}^{-1} \mathrm{~h}^{-1} \mathrm{ano}^{-1}$, com pontos de erosividade muito elevados. Nas coordenadas de 6707.950 e 780-7.900 verifica-se o maior índice de erosividade da região: na ordem de $18.000 \mathrm{MJ} \mathrm{mm}$ $\mathrm{ha}^{-1} \mathrm{~h}^{-1}$ ano $^{-1}$. Valores altos para essa região também foram obtidos por Mello et al. (2007) e Oliveira et al. (2009), os quais encontraram uma faixa de valores elevados que corta o Estado de Minas Gerais no sentido leste a noroeste. Segundo eles, a distribuição das chuvas mostra valores mensais mais elevados para a região do Vale do Rio Doce, onde são registrados os maiores valores de erosividade anual média - em alguns 
Quadro 4. Parâmetros dos semivariogramas teóricos ajustados pelo Método dos Quadrados Mínimos Ordinários (Ordinary Least Squares - OLS) para o índice de erosividade anual e mensal na região do Vale do Rio Doce, MG

\begin{tabular}{|c|c|c|c|c|c|}
\hline Período & Variância & $\mathbf{a}$ & Co & $\mathrm{C}+\mathrm{Co}$ & Modelo \\
\hline Anual & 5.962 .410 & 52 & 480.771 & 6.329 .069 & Gaussiano \\
\hline Janeiro & 601.837 & 30 & 29.202 & 648.037 & Gaussiano \\
\hline Fevereiro & 69.988 & 33 & 1.179 & 63.218 & Gaussiano \\
\hline Março & 117.461 & 35 & 11.916 & 108.784 & Gaussiano \\
\hline Abril & 23.076 & 20 & 4.574 & 14.907 & Gaussiano \\
\hline Maio & 4.760 & 33 & 621 & 3.829 & Gaussiano \\
\hline Junho & 2.591 & 177 & 141 & 2.476 & Exponencial \\
\hline Julho & 2.419 & 25 & 272 & 2.061 & Gaussiano \\
\hline Agosto & 3.010 & 27 & 482 & 2.417 & Gaussiano \\
\hline Setembro & 5.226 & 31 & 879 & 4.344 & Gaussiano \\
\hline Outubro & 34.957 & 10 & 7.617 & 31.991 & Gaussiano \\
\hline Novembro & 279.916 & 75 & 0 & 314.160 & Esférico \\
\hline Dezembro & 644.717 & 57 & 0,00027 & 709.183 & Esférico \\
\hline
\end{tabular}

a: alcance $(\mathrm{km}) ; \mathrm{C}_{0}$ : efeito pepita; $\mathrm{C}+\mathrm{C}_{0}$ : patamar.
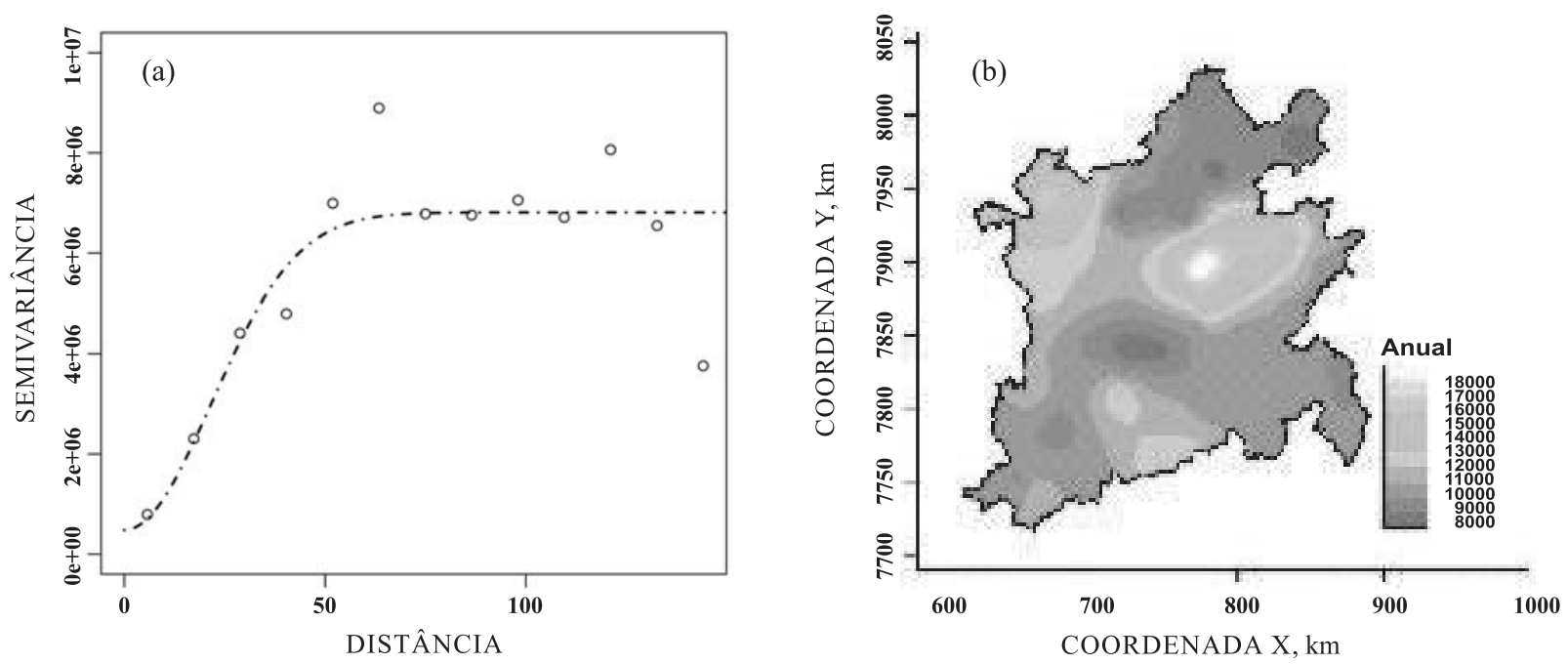

Figura 2. Semivariograma (a) e espacialização da erosividade anual (b) para a região do Vale do Rio Doce, MG.

casos, superiores a $10.000 \mathrm{MJ} \mathrm{mm} \mathrm{ha}^{-1} \mathrm{~h}^{-1} \mathrm{ano}^{-1}$. Entretanto, vale ressaltar que os valores verificados por esses autores para essa região foram obtidos de uma única equação, ajustada com dados de um ano. Os valores obtidos neste trabalho foram desenvolvidos a partir de equações ajustadas para nove municípios que dispunham de dados pluviográficos de quatro anos, os quais possibilitaram a determinação da erosividade para outros municípios que continham dados pluviométricos, permitindo gerar os mapas de espacialização da erosividade com maior grau de detalhe.

Os semivariogramas ajustados para a erosividade mensal e os mapas de espacialização do índice de erosividade mensal podem ser vistos nas figuras $3 \mathrm{e}$ 4, respectivamente. É nítida a diferença na erosividade entre o inverno e o verão. Em geral, a região apresentou nos meses mais secos, como junho, julho e agosto, valores de erosividade abaixo de $80 \mathrm{MJ} \mathrm{mm} \mathrm{ha}^{-1} \mathrm{~h}^{-1}$ mês ${ }^{-1}$; os maiores valores encontram-se próximos a 200 MJ mm ha ${ }^{-1} \mathrm{~h}^{-1}$ mês $^{-1}$. Já nos meses mais chuvosos (novembro a março), a maior parte da região apresentou valores próximos a $3.000 \mathrm{MJ} \mathrm{mm} \mathrm{ha}^{-1} \mathrm{~h}^{-1} \mathrm{mês}^{-1} \mathrm{de}$ novembro a janeiro e $1.500 \mathrm{MJ} \mathrm{mm} \mathrm{ha}^{-1} \mathrm{~h}^{-1} \mathrm{mês}^{-1} \mathrm{em}$ fevereiro e março. A região apresentou valores de erosividade menores no mês de fevereiro do que no mês de março. Os meses de novembro e dezembro mostraram grande variabilidade nos valores de erosividade em relação aos demais, inclusive em relação a janeiro, o qual apresentou certa homogeneidade na erosividade para toda a região, porém com valores extremos em algumas localidades. 

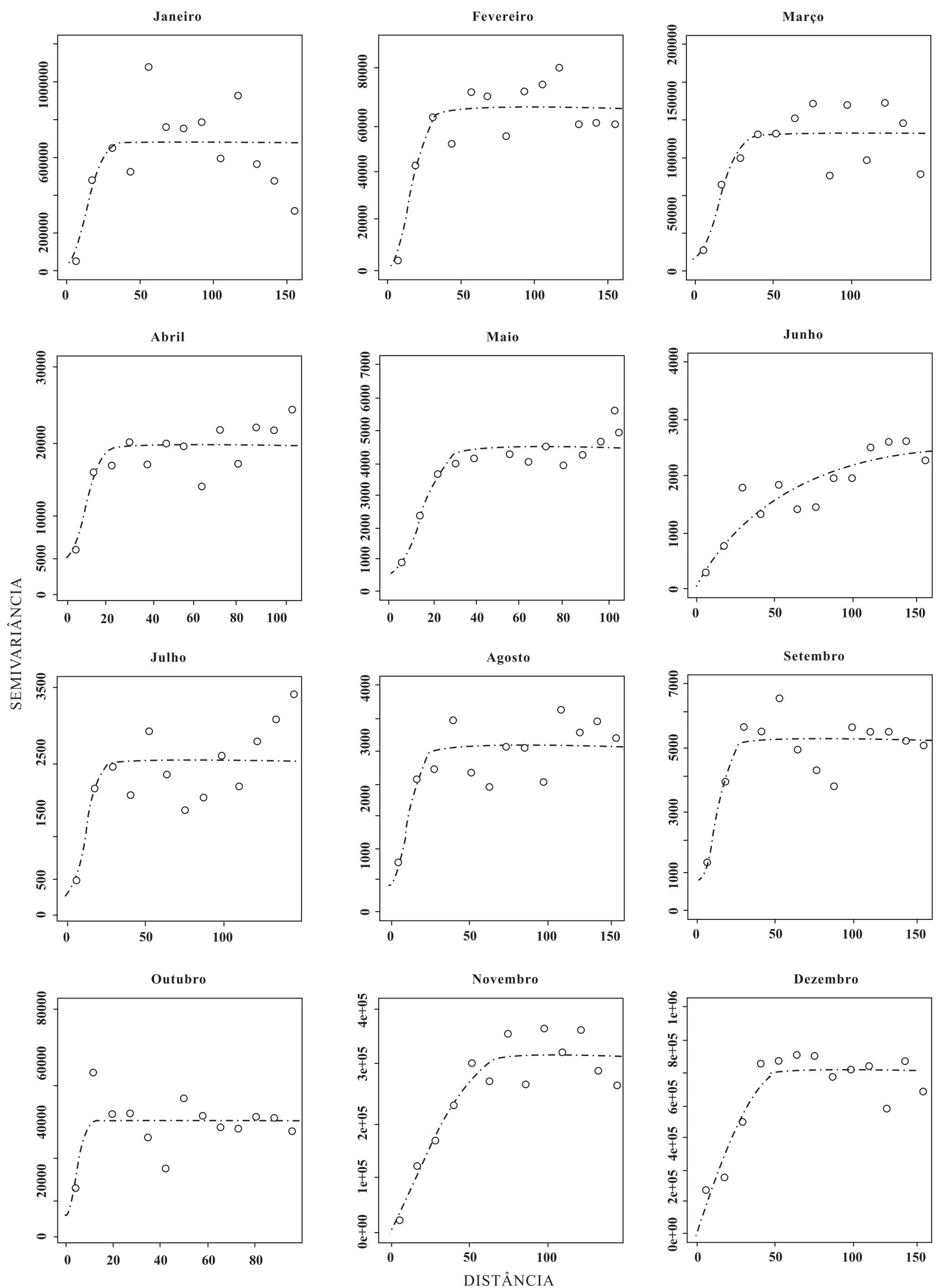

Figura 3. Semivariogramas ajustados para erosividade mensal para a região do Vale do Rio Doce, MG. 

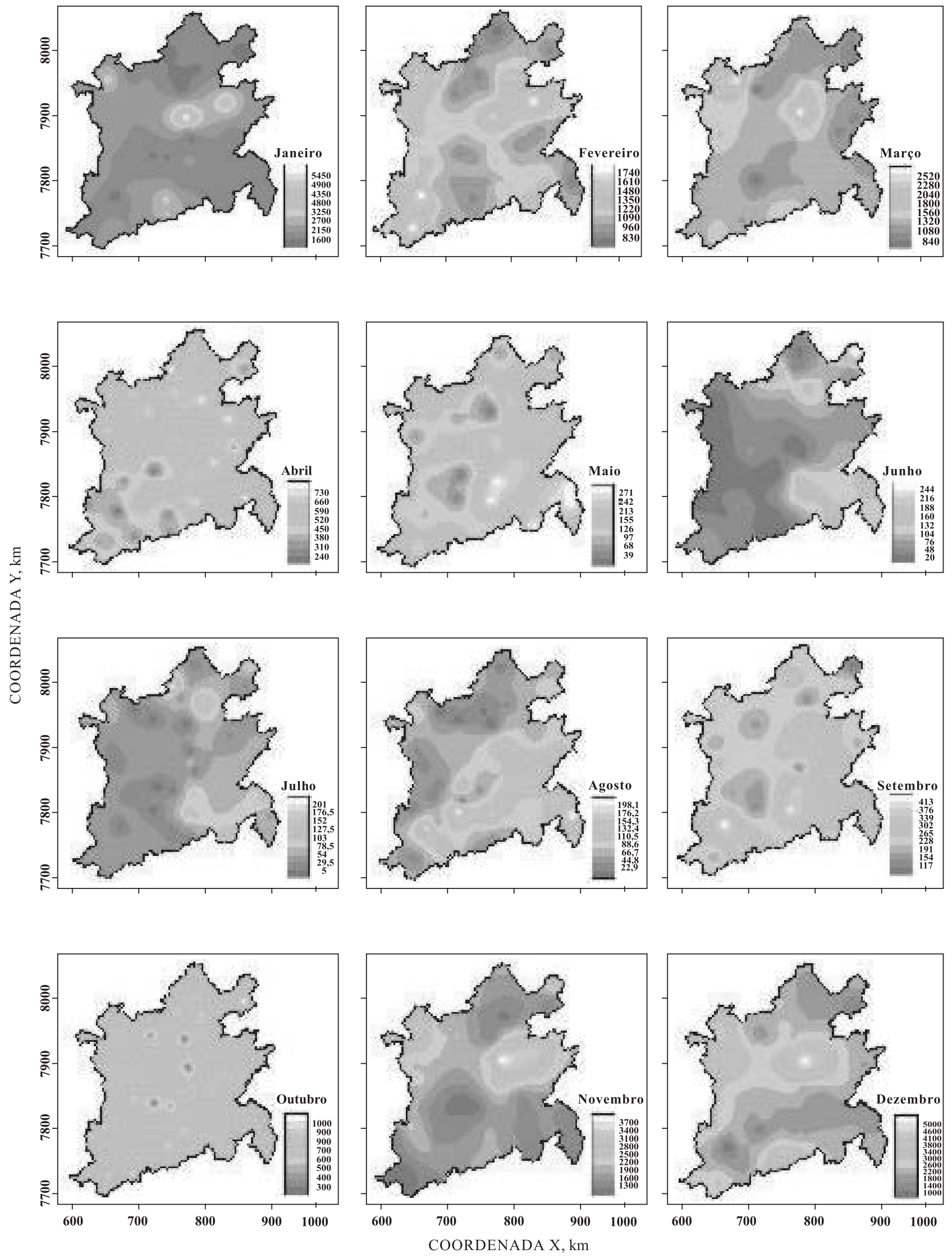

Figura 4. Espacialização da erosividade mensal na região do Vale do Rio Doce, MG. 


\section{CONCLUSÕES}

1. Os índices de erosividade anual variaram de 7.970 a $18.646 \mathrm{MJ} \mathrm{mm} \mathrm{ha}^{-1} \mathrm{~h}^{-1} \mathrm{ano}^{-1}$, considerados altos e muito altos, constituindo cenários críticos para o planejamento de práticas de conservação do solo e da água, particularmente desta última, numa região tão degradada pela erosão hídrica e com chuvas concentradas.

2. As técnicas de espacialização geoestatística em associação à interpolação dos dados por intermédio da krigagem mostraram-se promissoras para o mapeamento da erosividade da chuva em escala regional.

\section{LITERATURA CITADA}

ALBUQUERQUE, A.W., CHAVES, I.B. \& VASQUES FILHO, J. Características físicas da chuva correlacionadas com as perdas de solo num regolito eutrófico de Caruaru (PE), R. Bras. Ci. Solo, 18:279-283, 1994.

ALVES, M. Estimativa da perda de solo por erosão laminar na bacia do Rio São Bartolomeu - DF usando técnicas de geoprocessamento. São José dos Campos, 2000. 33p. (Relatório Técnico apresentado ao Instituto Nacional de Pesquisas Espaciais)

AQUINO, R.F. Padrões de chuva e variabilidade espacial da erosividade para o sul do Estado de Minas Gerais. Lavras, Universidade Federal de Lavras, 2005. 98p. (Tese de Mestrado)

BAZZANO, M.G.P.; ELTZ, F.L.F. \& CASSOL, E.A. Erosividade, coeficiente de chuva, padrões e período de retorno das chuvas de Quaraí, RS. R. Bras. Ci. Solo, 31:1205-1217, 2007.

BELO HORIZONTE. Secretaria de Estado de Ciência, Tecnologia e Ensino Superior - SECTES. Disponível em: $<$ http://www.sectes.mg.gov.br> 2008. Acesso em: 18 fev. 2008.

BERTOL, I. Índice de erosividade $\left(\mathrm{EI}_{30}\right)$ para Lages $(\mathrm{SC})-1^{\mathrm{a}}$ aproximação. Pesq. Agropec. Bras., 28:4:515-521,1993.

BERTONI, J. \& LOMBARDI NETO, F. Conservação do solo. São Paulo, Ícone, 1993. 355p.

CABRAL, J.B.P.; BECEGATO, V.A.; SCOPEL, I. \& LOPES, R.M. Estudo da erosividade e espacialização dos dados com técnicas de geoprocessamento na carta topográfica de Morrinhos-Goiás/Brasil para o período de 1971 a 2000. GeoFocus, 5:1-18, 2005.

CASSOL, E.A.; ELTZ, F.L.F.; MARTINS D.; LEMOS. A.M.; LIMA. V.S. \& BUENO, A.C. Erosividade, padrões hidrológicos, período de retorno e probabilidade de ocorrência das chuvas em São Borja, RS. R. Bras. Ci. Solo, 32:1239-1251, 2008.

CELULOSE NIPO BRASILEIRA S/A. - CENIBRA. Levantamento semidetalhado de solos das regiões do Rio Doce, Antônio Dias, Sabinópolis e Virginópolis. Ipatinga, 2001. 101p.
COGO, N.P. Conceitos e princípios envolvidos no manejo de solo para fins de controle da erosão hídrica. In: CONGRESSO BRASILEIRO DE CIÊNCIA DO SOLO, 21., Campinas, 1988. Anais... Campinas, Sociedade Brasileira de Ciência do Solo, 1988. p.251-262.

CUPOLILLO, F.; ABREU, M.L. \& CASTRO, F.V.F. Climatologia do regime pluviométrico na Bacia do Rio Doce. In: CONGRESSO BRASILEIRO DE METEOROLOGIA, 14. Florianópolis, 2006.. Anais. Florianópolis, 2006. p.1-7.

DE MARIA, I.C. Cálculo da erosividade da chuva. In: INSTITUTO AGRONÔMICO DE CAMPINAS. Manual de programas de processamento de dados de campo e de laboratório para fins de experimentação em conservação do solo. Campinas, IAC-SCS, 1994. não paginado.

DIAS, A.S. \& SILVA, J.R.C.A. Erosividade das chuvas em Fortaleza (CE). I - Distribuição, probabilidade de ocorrência e período de retorno - $1^{a}$ aproximação. R. Bras. Ci. Solo, $27: 335-345,2003$

FOSTER, G.R.; McCOOL, D.K.; RENARD, K.G. \& MOLDENHAUER, W.C. Conversion of the universal soil loss equation to SI units. J. Soil Water Conserv., 36:355359, 1981.

FOURNIER, F. The effect of climatic factors on soil erosion estimates of solids transported in suspension in runoff. [S.L.], Association Hydrologic Int. Public., 1956. v.38. 6p.

HUDSON, N. Soil conservation. 2.ed. Ithaca, Cornell University Press, 1971. 320p.

HUDSON, N. Soil conservation. Ames, Iowa State University Press, 1995. 391p.

GONÇALVES, F.A.; SILVA, D.D.; PRUSKI, F.F.; CARVALHO, D.F. \& CRUZ, E.S. Índices e espacialização da erosividade das chuvas para o Estado do Rio de Janeiro. R. Bras. Eng. Aagríc. Amb., 10:269-276, 2006.

Oliveira, J.A.; GUimarães, E.C. \& TAVARES, M. Comportamento espacial de chuvas de verão no estado de Minas Gerais. In: REUNIÃO ANUAL DA REGIÃO BRASILEIRA DA SOCIEDADE INTERNACIONAL DE BIOMETRIA, 50., 2005, Londrina. Anais... Londrina: [s.n.], 2005. 1 CD-ROOM.

JOURNEL, A.G. Fundamentals of geoestatistics in five lessons. Washington, American Geophysical Union, 1989. 40p.

LANDIM, P.M.B. Análise estatística de dados geológicos. São Paulo, UNESP, 1998. 226p.

LOMBARDI NETO, R. Rainfall erosivity - its distribution and relationship with soil loss at Campinas, Brasil. West Lafayette, Purdue University,1977. 53 p. (Tese de Mestrado)

MARTINS, S.G. Erosão hídrica em povoamentos de eucalipto sobre solos coesos nos Tabuleiros Costeiros, ES. Lavras, Universidade Federal de Lavras, 2005. 106p. (Tese de Doutorado)

MELLO, C.R.; SÁ, M.A.C.; CURI, N.; MELLO, J.M. \& VIOLA, M.R. Erosividade mensal e anual da chuva no Estado de Minas Gerais. Pesq. Agropec. Bras., 42:537-545, 2007.

MEN, M.; YU, Z. \& XU, H. Study on the spatial pattern of rainfall erosivity based on geostatistics in Hebei Province, China. Front. Agric. China, 2:281-289, 2008. 
MONTEBELLER, C.A.; CEDDIA, CARVALHO, D.F.; VIEIRA, S.R. \& FRANCO, E.M. Variabilidade espacial do potencial erosivo das chuvas no Estado do Rio de Janeiro. Eng. Agríc., 27:426-435, 2007.

MORAIS, L.F.B.; SILVA, V.; NASCHENVENG, T.M.C.; HARDOIN, P.C.; ALMEIDA, J.E.L.; WEBER, O.L.S.; BOEL, E. \& DURIGON, V. Índice $\mathrm{EI}_{30}$ e sua relação com o coeficiente de chuva do sudoeste do Mato Grosso. R. Bras. Ci. Solo, 15:339-344, 1991.

OLIVEIRA, F.P.; SILVA, M.L.N.; CURI, N.; SILVA, M.A. \& MELLO, C.R. Potencial erosivo da chuva no Vale do Rio Doce, região Centro-Leste do Estado de Minas Gerais Primeira aproximação. R. Ci. Agrotec., 33:1569-1577, 2009.

OLIVEIRA JÚNIOR, R.C. \& MEDINA, B.F. A erosividade das chuvas em Manaus (AM). R. Bras. Ci. Solo, 14:235-239, 1990.

RIBEIRO JUNIOR, P.J. \& DIGGLE, P.J. GeoR: A package for geoestatistical analysis. R-News, 1:15-18, 2001. Disponível em: <http://cran.r-project.org/doc/Rnews>. Acesso em: 15 mar. 2009.

RUFINO, R.L. Avaliação do potencial erosivo da chuva para o Estado do Paraná: Segunda aproximação. R. Bras. Ci. Solo, 10:279-281, 1986.

SALAKO, F.K.; GHUMAN, B.S. \& LAL, R. Rainfall erosivity in South-Central Nigeria. Soil Technol., 7:279-290, 1995.
SILVA, J.R.C. \& DIAS, A.S. A erosividade das chuvas em Fortaleza (CE): II - correlação com o coeficiente de chuva e atualização do fator $\mathrm{R}$ no período de 1962 a 2000 . R. Bras. Ci. Solo, 27:347-354, 2003.

SOCIEDADE BRASILEIRA DE SILVICULTURA - SBS. 2001. Disponível em: < http://www.sbs.org.br> 2001. Acesso em: 18 fev. 2008.

SILVA, A.M. Rainfall erosivity map for Brazil. Catena, 57:251259, 2004.

SOUZA, M.J.H.; RIBEIRO, A.; LEITE, H.G.; LEITE, F.P. \& MINUZZI, R.B. Disponibilidade hídrica do solo e produtividade do eucalipto em três regiões da Bacia do Rio Doce. R. Árvore, 30:399-410, 2006.

VIEIRA, S.R. \& LOMBARDI NETO, F. Variabilidade espacial do potencial de erosão das chuvas do Estado de São Paulo. Bragantia, 54:405-412, 1995.

WISCHMEIER, W.H. \& SMITH, D.D. Predicting rainfall erosion losses: A guide to conservation planning. Washington, USDA, 1978. 58p. (Agriculture Hand-Book, 537).

WISCHMEIER, W.H. \& SMITH, D.D. Rainfall energy and its relationships to soil loss. Trans. Am. Geophys. Union, 39:285-291, 1958

WISCHMEIER, W.H. Use and misuse of the universal soil loss equation. J. Soil Water Conserv., 31:5-9, 1976.

ZIMBACK, C.R.L. Geoestatística. Botucatu, FCA - UNESP, 2003. 25p. (Apostila) 